\title{
No Miracle Medicine for Eastern Renewal
}

A pragmatic blend of established measures for reorganizing central and eastern European research was envisaged by the Europhysics Study Conference on "Science Policy and Management" held at Schloss Dagstuhl, Germany, on 18-21 August.

As central and east European countries are considering departing from research organizations based on the prominent role of their respective Academies of Science, the EPS East-West Task Force thought it would be useful to compare information on how science is funded and structured elsewhere to see if some specific models are worth adopting. The Task Force made a recommendation along these lines in its report to the 1990 General Assembly at EPS-8 in Amsterdam, and the proposal for a workshop became a reality following vigorous work by the Action Committee for Physics and Society.

Leading research organizations were asked to send representatives who could describe how research in their countries was organized and how its quality was guaranteed. The response was excellent, and the number of invited participants was limited so that they could be accommodated in the IBFB computer association's remarkably beautiful but efficient Schloss Dagstuhl meeting centre in the Ruhr, Germany, arranged through the German Physical Society. The proceedings will summarize most of the 14 formal presentations, including those by representatives from CERN, NATO, the UK'S SERC, the French CNRS, Germany's DFG and Max Plank Gesellschaft, the Italian CNR, the Dutch FOM and NWO, Sweden's NFR, Switzerland's NF, and the Hungarian KFKI. Plenty of time was available for discussion to allow some recommendations to be worked out.

The main interest on the central European side was to learn how western research organizations operate and to explore possibilities for help in physics research. Participants from the west on the other hand, many of whom represented major research organizations, wished to compare approaches and hear about the present situation and future prospects for research in eastern Europe, including the rapid evolution in the former German Democratic Republic. All were struck by the remarkable forthrightness of eastern colleagues and their new spirit of open and constructive dialogue.

\section{Some Lessons}

There does not seem to be a homogeneous, exportable western European model: individual organization's have adapted to specific and general boundary conditions, and each is described by its own members with a mixture of pride, confidence and despair. One can only provide tentative suggestions rather than direct and strong advice, apart from the recommendation not to repeat mistakes and to "make your own and learn from them". National
Participants at the NATOsponsored Europhysics Study Conference

"Science Policy and Management", Schloss Dagstuhl, organized by the Action Committee for Physics and Society.

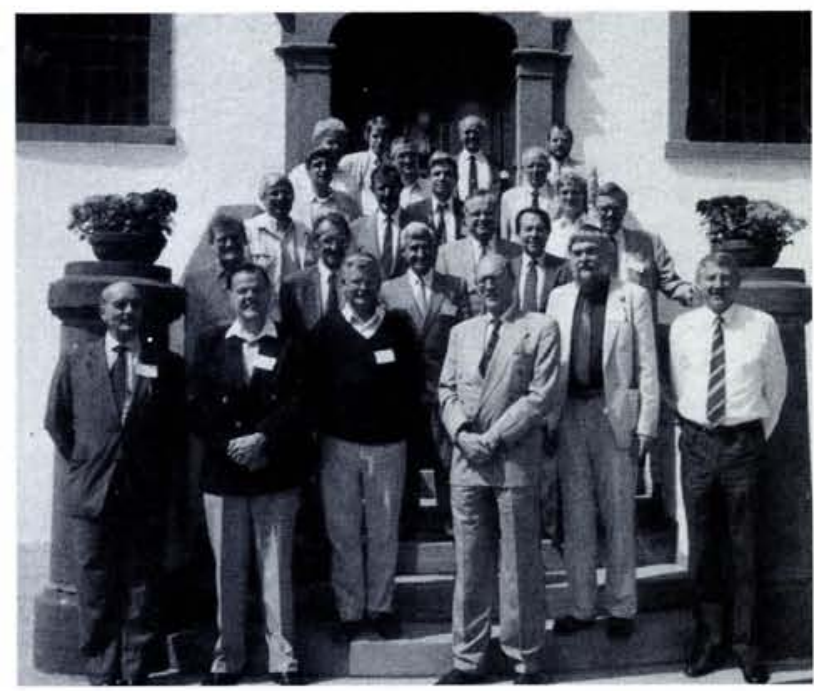

research systems must essentially be built up on a national basis according to particular arrangements as research funding is still largely structured this way. East-west collaboration ought thus be looked at mainly from within the framework of national organizations, although some international bodies can play a limited, but undoubtedly insufficient, pilot role in specific areas.

Physics itself can also play a pilot role, by starting collaboration schemes that later extend to other fields, as physics research is already "internationally minded". For it is relatively easy to access at a world-class level and high visibility often means one can soon see if a programme is successful or not. Both are important pluses. However, we live at a time when all of physics is not considered as a priority area by funding agencies so the call for help from eastern Europe comes at a difficult time. This is a minus we have to live with.

While an "ideal" model cannot be defined, there are some underlying and fundamentally sound principles which could be incorporated in new systems for science management. While basic work is mainly funded by governments, it should be administered by non-governmental agencies dominated by scientists with research quality assessed using peer review, panels and international refereeing independent of national administrations. Indeed, Professor Jolles, a sociologist, who was invited to comment on the discussions, remarked that all the western funding agencies present were proud to point out their non-governmental status so he felt this feature must be of prime importance. He also noted the importance of anonymous peer review, of trust in the fairness of procedures and of the application of the principle that decisions are based on reasoned argument and not on who said something.

Well-conceived schemes must also insist on long-term stable support and a steady influx of young scientists with the means to ensure good mobility. The key criterion for selecting priorities should be excellence while avoiding a clear dichotomy between pure and applied research. Although public funding agencies should encourage some oriented research, they ought not be more committed than industry itself in specific programmes involving applied topics. The $50 \%$ of physicists in western countries who work in industry benefitted greatly from the training provided by basic research, where they are generally no longer active. Thus, while industry should play the major role in develop innovation and applications, one must recognize the underlying importance of basic research.

\section{Scattered Resources}

Some pragmatic considerations set the stage for today's initiatives. Specifically, short-term actions can only be realistically considered within the context of constant budgets (hopefully in real terms) - we must get the most out of what we have. Apart from limited programmes, we cannot assume that any important funding will be set aside in western Europe to help physics research elsewhere. However, most western organizations appear willing to include eastern partners at the research team level, something they can implement within the context of existing collaborations. Many small sources of funding should therefore develop and the challenge is to exploit them in the best possible way.

On the other hand, Professor Jolles thought that since innovative actions in western countries seemed not to be done but through new units, one lesson might be that the necessary innovations in the science support system in the east could profit from the creation of new bodies. The best course may therefore be the middle road - innovative actions by new structures within today's organizations.

\section{International Laboratories}

Returning to a possible pivotal role for international organizations, it can argued that organizations and laboratories such as CERN, JET, ESA, IAEA, etc. offer an efficient way for small groups to quickly enter world-class basic research, by making carefully targetted inputs into international collaborations working under strict timetables at the frontiers of both scientific knowledge and technical capabilities. Far from considering resources devoted to the field concerthrough existing mechanisms and bodies, 
ned as a mere luxury for countries that still have a limited research base, active participation in major international science projects provides enormous stimulation, immediate access to tutorial support and a huge amount of data and information, and often the possibility to carry out significant tasks in the home country. Supporting membership of central and east European countries and their agencies in the larger internationally-based research organizations thus represents an attractive option for governments: encouraging such a strategy may effectively offer a way to envisage increased research funding in these countries.

\section{Pragmatic Mechanisms}

Given that renewal and development in east and central Europe will take at least a generation whereas only existing mechanisms and short term measures for support are available, Professor Jolles summarized the participants' main recommendations for future initiatives. They are:

- place refereeing on an international basis and call for international evaluation panels when internal groups are too small, homogeneous or manipulated;

- exploit membership and participation in international networks (ESF, Université de l'Europe, NATO, EEC, EPS, CERN, etc.);

- use western facilities with financial help for mobility;

- build up bilateral arrangements.

So there is no miracle medicine but a mixture of mechanisms: use whatever help exists as together you might be pushed over the mountain.

All who participated were very grateful for the generous financial support provided by the NATO Scientific Affairs Division that allowed useful options and working strategies to be discussed: they hoped a similar workshop along the same lines would be held in two to three years to evaluate progress - only this time outside western Europe.

\section{Jacob \\ EPS President
E.W.A. Lingeman Chairman Physics and Society}

\section{1st EPS Southern European School of Physics}

\section{Dynamical Processes in Molecular Physics}

\author{
Avila, Spain, 1-13 September 1991
}

As it is not usual for laboratories in southern Europe to pay for Ph.D. students to attend summer schools, the EPS Action Committee for Physics and Development launched a series of schools with a "southern emphasis", where funding would be provided to invited students. Thanks to the generosity of some key sponsors, notably the EC, NATO and some Spanish sources, the first EPS Southern School of Physics, held in the charming walled town of Avila, Spain, from 1-13 September, was a great success. There were 56 participants with lectures given by nearly 20 prominent experts: the Director of the School was Professor Gerado DelgadoBarrio from Madrid. The exciting topics covered included some particlarly interesting ones such as the physics of small molecular aggregates. An interesting novelty was introduced into the tutorials: participants were able to work with specially developed software on computers loaned in part by IBM Spain, and then take the programs away for later use.

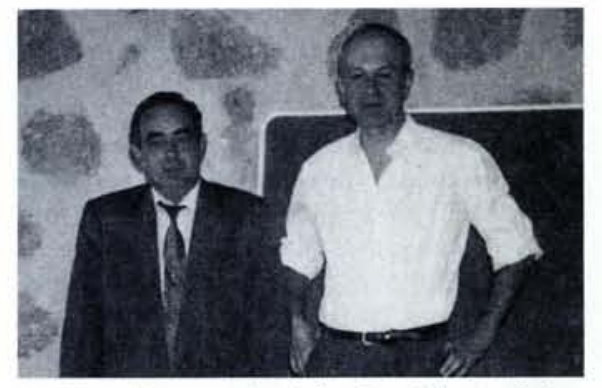

A. Tiemblo, on the left, President of the Royal Spanish Physical Society, and G. Delgado-Barrio, Director of the 1st EPS Southern European School of Physics.

The School is managed by an Advisory Board representing the Divisions, national societies and the main funding agencies. The Board is presently considering a proposal by Professor C. Fotakis on behalf of the Institute of Electronic Structure and Lasers of the Foundation for Research and Technology, Hellas, to hold the next school in Crete on Lasers and Applications.

\section{History of Physics Group Consolidates}

It is slightly over two years since EPS Council approved the formation of the Interdivisional Group for the History of Physics, which came together following the organization of conferences in Pavia (1983), Munich (1986) and Paris (1988) on the use of the history of science in physics teaching. Recent activities along the same lines include the organization of a conference "History Teaching Physics" (Cambridge, UK, August 1990) and of history of physics sessions at the EPS-8 General Conference in September 1990.

The Group continues to see as one of its aims the organization of meetings on the history of physics and on its application in science education. The Group's Chairman, Fabio Bevilacqua, Professor of Physics in Pavia University's Physics Department, is therefore very pleased to be able to announce that a project to hold the first-ever European History of Physics Conference has come to fruition: it will take place at the Villa Olmo in Como, Italy, in May 1992 and details will be available shortly.

Meanwhile, Dr. Antonio Moreno-Gonzalez of the Escuola Universitaria de Formación del Professorado, Universidad Complutense, Madrid, has sent out the first circular for a Europhysics Study Conference he is organizing titled "History of the Physical-Mathematical Sciences and the Teaching of Sciences" to be held at the University on 9-11 September 1992. This meeting will offer an opportunity for physics teachers from throughout Europe to discuss recent experience on the didactic applications of science history.

Other activities in the area of science teaching include a project to develop guidebooks for teachers, while the third of the Group's goals is to promote the preservation and cataloging of archives and collections of scientific instruments. 